Article

\title{
Numerical Study for Darcy-Forchheimer Flow of Nanofluid due to a Rotating Disk with Binary Chemical Reaction and Arrhenius Activation Energy
}

\author{
Mir Asma ${ }^{1}$, W.A.M. Othman ${ }^{1, *}$ and Taseer Muhammad ${ }^{2}$ \\ 1 Institute of Mathematical Sciences, Faculty of Science, University of Malaya, Kuala Lumpur 50603, Malaysia \\ 2 Department of Mathematics, Government College Women University, Sialkot 51310, Pakistan \\ * Correspondence: wanainun@um.edu.my
}

Received: 16 July 2019; Accepted: 11 September 2019; Published: 2 October 2019

check for updates

\begin{abstract}
The present article investigates Darcy-Forchheimer 3D nanoliquid flow because of a rotating disk with Arrhenius activation energy. Flow is created by rotating disk. Impacts of thermophoresis and Brownian dispersion are accounted for. Convective states of thermal and mass transport at surface of a rotating disk are imposed. The nonlinear systems have been deduced by transformation technique. Shooting method is employed to construct the numerical arrangement of subsequent problem. Plots are organized just to investigate how velocities, concentration, and temperature are influenced by distinct emerging flow variables. Surface drag coefficients and local Sherwood and Nusselt numbers are also plotted and discussed. Our results indicate that the temperature and concentration are enhanced for larger values of porosity parameter and Forchheimer number.
\end{abstract}

Keywords: Arrhenius activation energy; rotating disk; Darcy-Forchheimer flow; binary chemical reaction; nanoparticles; numerical solution

\section{Introduction}

Nanofluid is the blend of nanometer-measured particles and the conventional base liquid. Nanofluids are generally used to conquer the low warm exhibition of normal base liquids such as oil, water, ethylene glycol, and propylene glycol. Because of intriguing physical characteristics, the nanofluids have potential use in earthenware production, metal working procedures, covering related applications, atomic reactor cooling, cooling, transportation, attractive medication, and a few others. Choi and Eastman [1] are credited with the word nanofluid. They established that nanomaterials are remarkable candidates for development in warmth transport of ordinary fluids. Regarding the convective vehicle of nanofluid, a numerical relation is accounted by Buongiorno [2]. Here, thermophoresis and Brownian movement are viewed as the most significant slip instruments. A few ongoing progressions in nanofluid streams can be found in references [3-25].

The present examiners are associated with breaking down the liquid stream due to a turning disk because of its tremendous applications in rotational air cleaners, diffusive siphons, nourishment handling advances, turbomachinery, PC stockpiling gadgets, therapeutic hardware, gas turbine rotors, greases, pivoting plate cathodes, and numerous other examples. Initially, the pivoting plate issue was tended to by von Karman [26]. Cochran [27] created asymptotic answer for the von Karman issue. Stewartson [28] broke down liquid stream between pivoting co-axial plates. Chappel and Stirs [29] talked about the liquid stream among turning and stationary plate. Ackroyd [30] thought about suction/infusion impacts in the Karman issue and created arrangements containing exponentially rotting coefficients. Shaky progression of thick fluid instigated by noncoaxial turns of a disk was explained by Erdogan [31]. Attia [32] talked about liquid stream by turning circles submerged in a 
permeable space using Wrench Nicolson strategy. Warmth and mass exchange attributed to pivoting streams of thick fluid because of a permeable circle was analyzed by Turkyilmazoglu and Senel [33]. They registered the numerical arrangement of the overseeing stream issue. Rashidi et al. [34] inspected the impact of entropy in a hydromagnetic stream of viscous liquid by pivoting plate. Mustafa et al. [35] investigated the progression of nanoliquid actuated by an extending circle. They inferred that constant extending of disk is a significant part of lessening limit-layer thickness. Hydromagnetic stream of a turning plate by taking slip and nanoparticles impacts was examined by Hayat et al. [36]. Mustafa [37] analyzed MHD nanoliquid flow by turning disk subjects to slip impacts. Hayat et al. [38] discussed the Darcy-Forchheimer stream of CNTs instigated by turning disk.

Concentration difference of species exists in a blend, subject to mass exchange. By fluctuating the grouping of species in a blend, they move from a high-fixation area to low-focus locale. The least compulsory vitality that is needed by reactants before synthetic response occurs is characterized as enactment vitality. A mass exchange mechanism alongside substance response with enactment vitality for the most part discovers applications in concoction building, mechanics of oil, and water emulsions, nourishment preparation etc. The regular convection stream of double-blend in a permeable medium with initiation vitality was proposed by Bestman [39]. Makinde et al. [40] explored temperamental characteristic convection stream subject to nth-request response and initiation vitality. Maleque [41] studied exothermic/endothermic response in blended convection streams subject to initiation vitality. Adjusted Arrhenius capacity was used by Awad et al. [42] to examine shaky pivoting streams of two-fold liquid past an indiscreet twisted surface. Abbas et al. [43] explored casson liquid streams subject to actuation vitality. Shafique et al. [44] inspected turning visco-elastic streams joining artificially receptive species with initiation vitality. Further recent attempts on binary chemical reaction and Arrhenius activation energy can be seen in the studies [45-47].

Darcy-Forchheimer nanoliquid flow because of rotating disk subject to binary chemical reaction and Arrhenius activation energy is investigated. Thermophoretic dispersion and arbitrary movement viewpoints are held. Heat and mass exchange highlights are broken down via convective factors. The administrative frameworks are comprehended numerically through shooting procedure. Additionally, velocities, concentration, temperature, surface drag coefficients, and local Sherwood and Nusselt numbers are discussed graphically.

\section{Statement}

Here, steady, laminar Darcy-Forchheimer 3D flow of viscous nanoliquid because of a rotating disk with binary chemical reaction and Arrhenius activation energy is examined. The disk at $z=0$ rotates with constant angular velocity $\Omega$ (see Figure 1). Effects of thermophoresis and Brownian dissemination are additionally accounted for. Convection factors for warmth and mass exchange are employed. It is additionally accepted that the surface is warmed by hot liquid with concentration $C_{f}$ and temperature $T_{f}$ that give mass and warmth exchange coefficients $k_{m^{\star}}$ and $h_{f}$ respectively. Velocities are $(u, v, w)$ in directions of $(r, \varphi, z)$ separately. Ensuing boundary layer articulations are [22,38,44]:

$$
\begin{gathered}
\frac{\partial u}{\partial r}+\frac{u}{r}+\frac{\partial w}{\partial z}=0 \\
u \frac{\partial u}{\partial r}-\frac{v^{2}}{r}+w \frac{\partial u}{\partial z}=v\left(\frac{\partial^{2} u}{\partial z^{2}}+\frac{\partial^{2} u}{\partial r^{2}}+\frac{1}{r} \frac{\partial u}{\partial r}-\frac{u}{r^{2}}\right)-\frac{v}{k^{*}} u-F u^{2}, \\
u \frac{\partial v}{\partial r}+\frac{u v}{r}+w \frac{\partial v}{\partial z}=v\left(\frac{\partial^{2} v}{\partial z^{2}}+\frac{\partial^{2} v}{\partial r^{2}}+\frac{1}{r} \frac{\partial v}{\partial r}-\frac{v}{r^{2}}\right)-\frac{v}{k^{*}} v-F v^{2}, \\
u \frac{\partial w}{\partial r}+w \frac{\partial w}{\partial z}=v\left(\frac{\partial^{2} w}{\partial z^{2}}+\frac{\partial^{2} w}{\partial r^{2}}+\frac{1}{r} \frac{\partial w}{\partial r}\right)-\frac{v}{k^{*}} w-F w^{2},
\end{gathered}
$$




$$
\begin{aligned}
u \frac{\partial T}{\partial r}+w \frac{\partial T}{\partial z} & =\alpha^{*}\left(\frac{\partial^{2} T}{\partial z^{2}}+\frac{\partial^{2} T}{\partial r^{2}}+\frac{1}{r} \frac{\partial T}{\partial r}\right) \\
& +\frac{(\rho c)_{p}}{(\rho c)_{f}}\left(D_{B}\left(\frac{\partial T}{\partial r} \frac{\partial C}{\partial r}+\frac{\partial T}{\partial z} \frac{\partial C}{\partial z}\right)+\frac{D_{T}}{T_{\infty}}\left(\left(\frac{\partial T}{\partial z}\right)^{2}+\left(\frac{\partial T}{\partial r}\right)^{2}\right)\right), \\
u \frac{\partial C}{\partial r}+w \frac{\partial C}{\partial z} & =D_{B}\left(\frac{\partial^{2} C}{\partial z^{2}}+\frac{\partial^{2} C}{\partial r^{2}}+\frac{1}{r} \frac{\partial C}{\partial r}\right) \\
& +\frac{D_{T}}{T_{\infty}}\left(\frac{\partial^{2} T}{\partial z^{2}}+\frac{\partial^{2} T}{\partial r^{2}}+\frac{1}{r} \frac{\partial T}{\partial r}\right)-k_{r}^{2}\left(C-C_{\infty}\right)\left(\frac{T}{T_{\infty}}\right)^{n} \exp \left(-\frac{E_{a}}{\kappa T}\right) .
\end{aligned}
$$

Subjected boundary conditions are

$$
\begin{gathered}
u=0, v=r \Omega, w=0,-k \frac{\partial T}{\partial z}=h_{f}\left(T_{f}-T\right), \quad-D_{B} \frac{\partial C}{\partial z}=k_{m^{*}}\left(C_{f}-C\right) \text { at } z=0, \\
u \rightarrow 0, \quad v \rightarrow 0, \quad T \rightarrow T_{\infty}, \quad C \rightarrow C_{\infty} \text { as } z \rightarrow \infty .
\end{gathered}
$$

Here $u, v$ and $w$ represent velocities in directions of $r, \phi$ and $z$ while $\rho_{f}, v\left(=\mu / \rho_{f}\right)$ and $\mu$ show density, kinematic and dynamic viscosities respectively, $(\rho c)_{p}$ effective heat capacity of nanoparticles, $E_{a}$ the activation energy, $(\rho c)_{f}$ heat capacity of liquid, $k^{*}$ the permeability of porous space, $C$ the concentration, $n$ the fitted rate constant, $C_{\infty}$ the ambient concentration, $F=C_{b} / r k^{*^{1 / 2}}$ the non-uniform inertia factor, $D_{T}$ the thermophoretic factor, $C_{b}$ the drag factor, $h_{f}$ the uniform heat transfer factor, $\alpha^{*}=k /(\rho c)_{f}$ and $k$ the thermal diffusivity and thermal conductivity respectively, $T$ the fluid temperature, $k_{r}$ the reaction rate, $D_{B}$ the Brownian factor, $\kappa$ the Boltzmann constant, $k_{m^{*}}$ the uniform mass transfer factor and $T_{\infty}$ the ambient temperature. Selecting

$$
\left.\begin{array}{c}
u=r \Omega f^{\prime}(\zeta), w=-(2 \Omega v)^{1 / 2} f(\zeta), v=r \Omega g(\zeta), \\
\phi(\zeta)=\frac{C-C_{\infty}}{C_{f}-C_{\infty}}, \zeta=\left(\frac{2 \Omega}{v}\right)^{1 / 2} z, \theta(\zeta)=\frac{T-T_{\infty}}{T_{f}-T_{\infty}} .
\end{array}\right\}
$$

Continuity expression (1) is verified while Equations (2)-(8) yield

$$
\begin{gathered}
2 f^{\prime \prime \prime}+2 f f^{\prime \prime}-f^{\prime^{2}}+g^{2}-\lambda f^{\prime}-F r f^{\prime^{2}}=0, \\
2 g^{\prime \prime}+2 f g^{\prime}-2 f^{\prime} g-\lambda g-F r g^{2}=0, \\
\frac{1}{\operatorname{Pr}} \theta^{\prime \prime}+f \theta^{\prime}+N_{b} \theta^{\prime} \phi^{\prime}+N_{t} \theta^{\prime 2}=0, \\
\frac{1}{S c} \phi^{\prime \prime}+f \phi^{\prime}+\frac{1}{S c} \frac{N_{t}}{N_{b}} \theta^{\prime \prime}-\sigma(1+\delta \theta)^{n} \phi \exp \left(-\frac{E}{1+\delta \theta}\right)=0, \\
f(0)=0, f^{\prime}(0)=0, g(0)=1, \theta^{\prime}(0)=-\gamma_{1}(1-\theta(0)), \phi^{\prime}(0)=-\gamma_{2}(1-\phi(0)), \\
f^{\prime}(\infty) \rightarrow 0, g(\infty) \rightarrow 0, \theta(\infty) \rightarrow 0, \phi(\infty) \rightarrow 0 .
\end{gathered}
$$

Here $\mathrm{Fr}$ stands for Forchheimer number, $\gamma_{2}$ for concentration Biot number, $\lambda$ for porosity parameter, $\gamma_{1}$ for thermal Biot number, $N_{t}$ thermophoresis parameter, Pr Prandtl number, $\sigma$ for chemical reaction parameter, $N_{b}$ for Brownian motion, $\delta$ for temperature difference parameter, $S c$ Schmidt number, and $E$ for nondimensional activation energy. Nondimensional variables are defined by

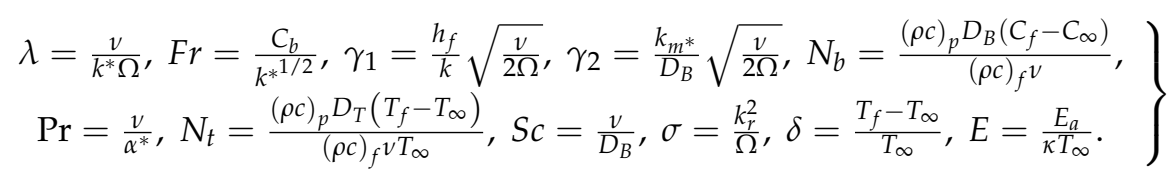


The coefficients of skin-friction and Nusselt and Sherwood expressions are

$$
\left.\begin{array}{c}
\operatorname{Re}_{r}^{1 / 2} C_{f}=f^{\prime \prime}(0), \operatorname{Re}_{r}^{1 / 2} C_{g}=g^{\prime}(0), \\
\operatorname{Re}_{r}^{-1 / 2} N u=-\theta^{\prime}(0), \operatorname{Re}_{r}^{-1 / 2} S h=-\phi^{\prime}(0),
\end{array}\right\}
$$

where $\operatorname{Re}_{r}=2(\Omega r) r / v$ represents local rotational Reynolds number.

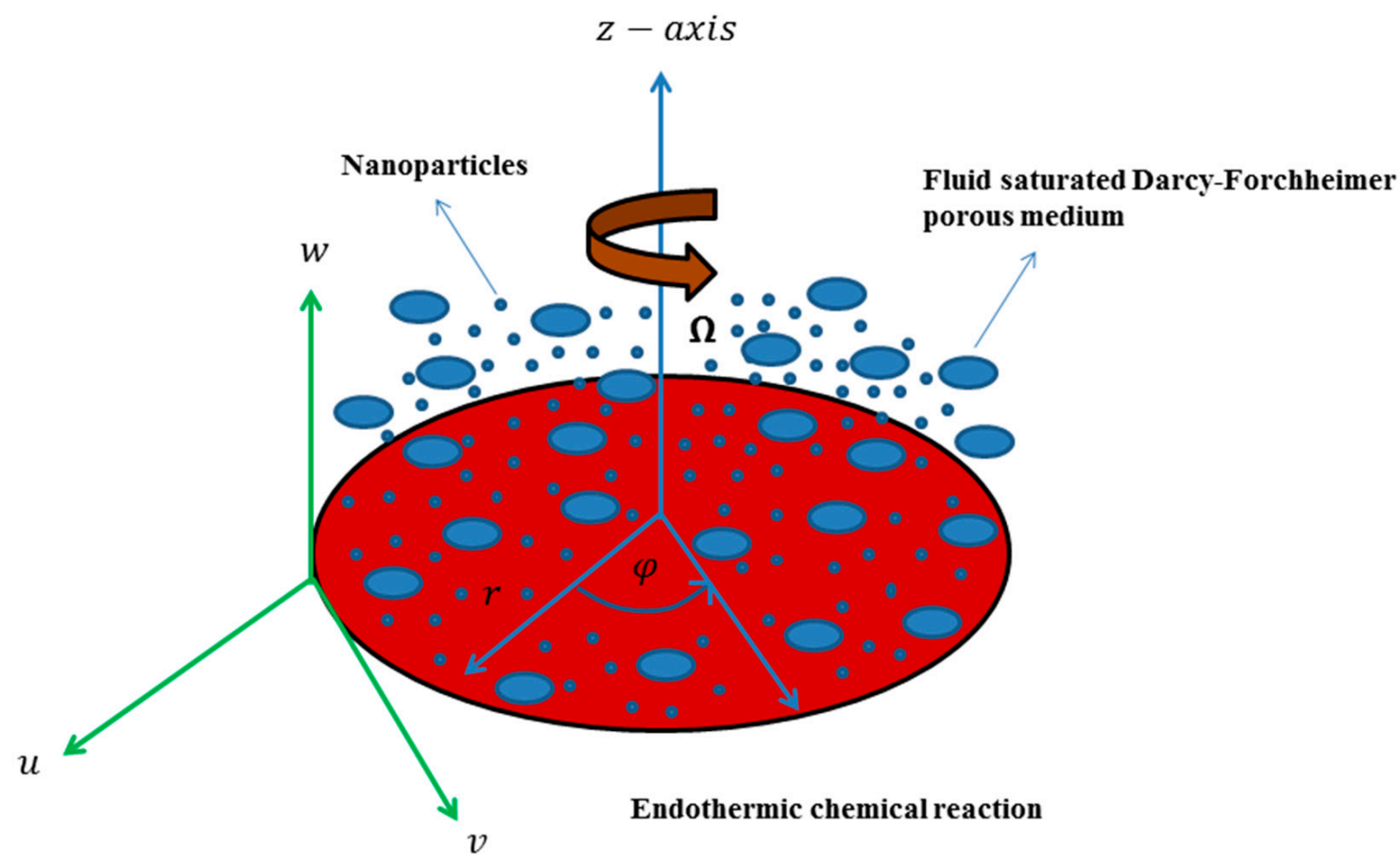

Figure 1. Flow configuration.

\section{Numerical Results and Discussion}

The present section outlines the commitment of various relevant parameters including Schmidt number $S c$, porosity parameter $\lambda$, thermophoresis parameter $N_{t}$, Prandtl number Pr, Forchheimer number $F r$, nondimensional activation energy $E$, thermal Biot $\gamma_{1}$, chemical reaction parameter $\sigma$, concentration Biot $\gamma_{2}$ and Brownian number $N_{b}$ on velocities $f^{\prime}(\zeta)$ and $g(\zeta)$, concentration $\phi(\zeta)$ and temperature $\theta(\zeta)$ distributions. Figure 2 portrays how porosity parameter $\lambda$ influences the speed appropriation $f^{\prime}(\zeta)$. It has been discovered that the speed profile $f^{\prime}(\zeta)$ and its related energy layer are devalued by upgrading porosity $\lambda$. The presence of permeable space improves the protection from liquid stream which relates to bringing down liquid speed and its related energy layer. Figure 3 delineates the impact of Forchheimer variable Fr on $f^{\prime}(\zeta)$. Higher estimations of Forchheimer variable Fr establish lower speed profile $f^{\prime}(\zeta)$. Figure 4 shows how the speed conveyance $g(\zeta)$ is influenced by porosity parameter $\lambda$. Here the speed dissemination is rotted by expanding $\lambda$. Figure 5 delineates a variety of speed circulation $g(\zeta)$ for unmistakable Fr. By expanding Fr, a decrease showed up in speed dissemination and related layer. Figure 6 shows warm Biot $\gamma_{1}$ impact on temperature $\theta(\zeta)$. More grounded convection is delivered by upgrading warm Biot number $\gamma_{1}$. Thus, temperature and warm layer are raised by expanding warm Biot number $\gamma_{1}$. Figure 7 presents a variety in temperature field $\theta(\zeta)$ for Pr. Here, temperature is rotted for bigger Pr. The proportion of force diffusivity to warm diffusivity is termed as the Prandtl number. Higher estimations of Pr depict more fragile warm diffusivity, which compares to diminishing in the warm layer. Figure 8 is shown to investigate $N_{t}$ impact on temperature field $\theta(\zeta)$. Bigger thermophoresis parameter $N_{t}$ establishes a higher temperature field and progressively warm layer thickness. The purpose of such contention is that augmentation in $N_{t}$ yields high grounded thermophoresis power which further permits motion of 
the nanoparticles in liquid zone. Far from surface in this way shapes a more grounded temperature dispersion $\theta(\zeta)$ and progressively warm layer. The effect of $N_{b}$ on temperature profile $\theta(\zeta)$ is depicted in Figure 9. From a physical perspective, an unpredictable movement of nanoparticles increments by improving Brownian movement parameter $N_{b}$ causes a crash of particle. As a result, the active vitality is changed into warmth vitality which causes upgrade in $\theta(\zeta)$ and associated warm layer. Figure 10 shows how concentration $\phi(\zeta)$ is influenced by concentration Biot number $\gamma_{2}$. Concentration is upgraded for higher estimations of $\gamma_{2}$. From Figure 11 we can see that bigger Sc rots concentration $\phi(\zeta)$. Schmidt number Sc is conversely relative to Brownian diffusivity. Higher Sc yields a more fragile Brownian diffusivity. Such Brownian diffusivity prompts low concentration $\phi(\zeta)$. Figure 12 demonstrates how the thermophoresis parameter $N_{t}$ influences the concentration $\phi(\zeta)$. By improving thermophoresis parameter $N_{t}$, concentration $\phi(\zeta)$ and related concentration layers are upgraded. Figure 13 depicts the Brownian movement $N_{b}$ and minor departure from concentration $\phi(\zeta)$. It can be seen that a more fragile concentration $\phi(\zeta)$ is produced by using higher $N_{b}$. Figure 14 explains the impact of nondimensional initiation vitality $\mathrm{E}$ on concentration $\phi(\zeta)$. An improvement in $\mathrm{E}$ rots altered Arrhenius work $\left(\frac{T}{T_{\infty}}\right)^{n} \exp \left(-\frac{E_{a}}{\kappa T}\right)$. Such inevitably builds up the generative synthetic response because of which concentration $\phi(\zeta)$ upgrades. Figure 15 shows that an improvement in $\sigma$ shows a rot in concentration $\phi(\zeta)$ and its related layer. Highlights of $N_{t}$ and $N_{b}$ on $N u\left(\operatorname{Re}_{r}\right)^{-1 / 2}$ are revealed through Figures 16 and 17 respectively. True to form, $N u\left(\operatorname{Re}_{r}\right)^{-1 / 2}$ reduces for $N_{t}$ and $N_{b}$. Effects of $N_{t}$ and $N_{b}$ on $\operatorname{Sh}\left(\operatorname{Re}_{r}\right)^{-1 / 2}$ have been portrayed in Figures 18 and 19 respectively. Here $\operatorname{Sh}\left(\operatorname{Re}_{r}\right)^{-1 / 2}$ is an expanding capacity of $N_{t}$, while the inverse pattern is seen for $N_{b}$. Table 1 is developed to validate the present results with the previously published results in a limiting case. Here, we demonstrate that the present numerical solution has good agreement with the previous solution by Naqvi et al. [48] in a limiting case.

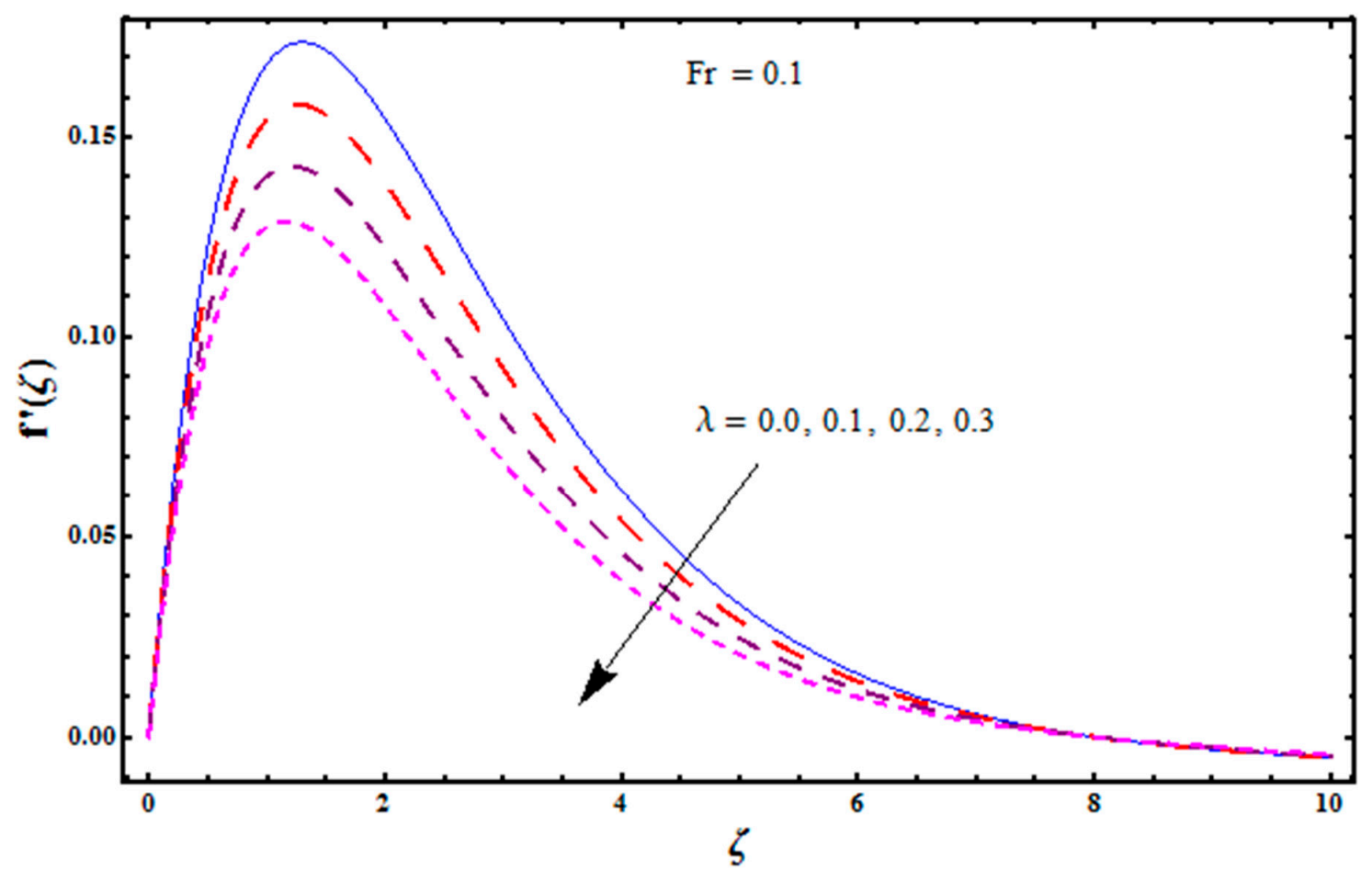

Figure 2. Curves of $f^{\prime}(\zeta)$ for $\lambda$. 


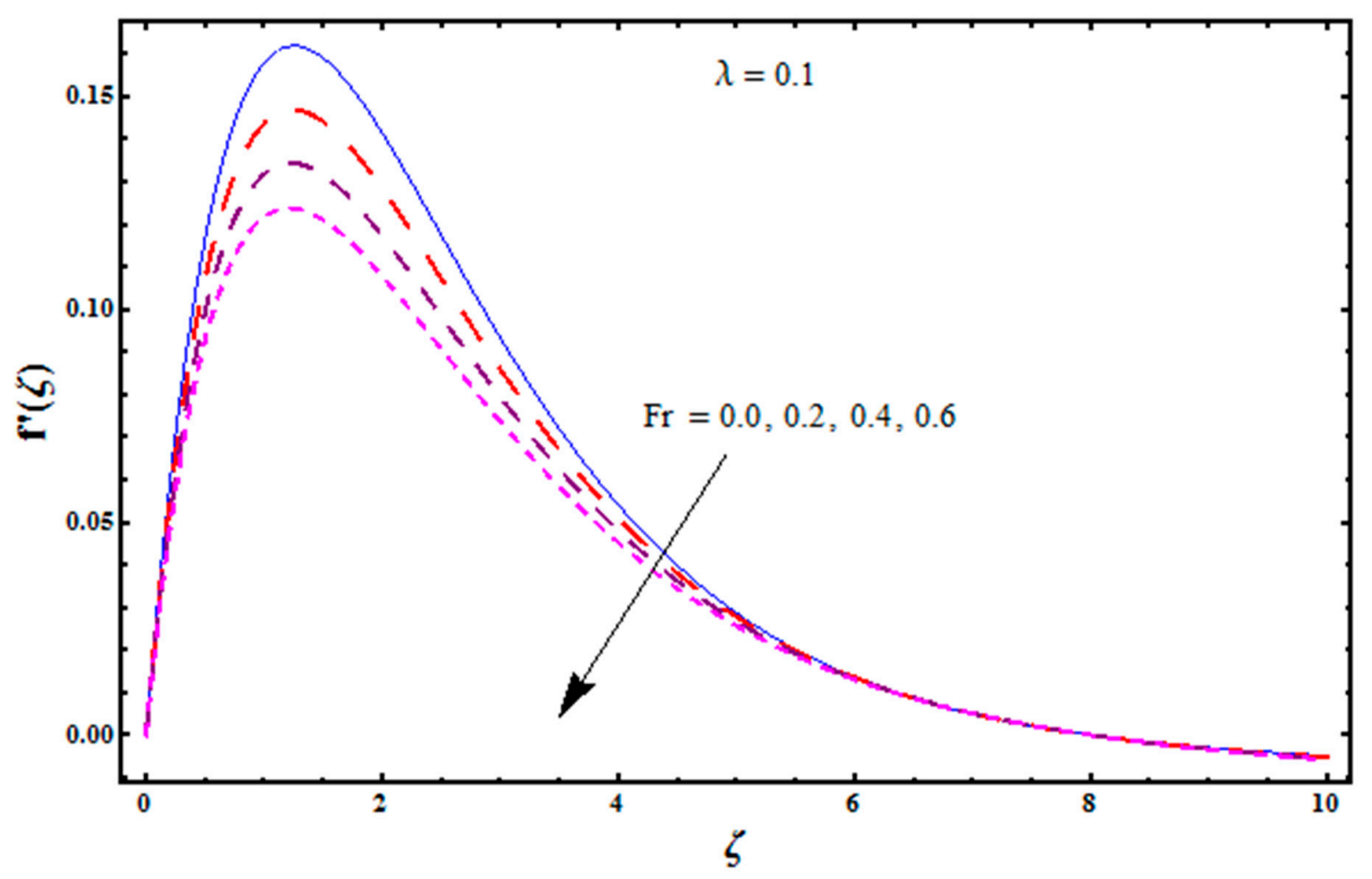

Figure 3. Curves of $f^{\prime}(\zeta)$ for $F r$.

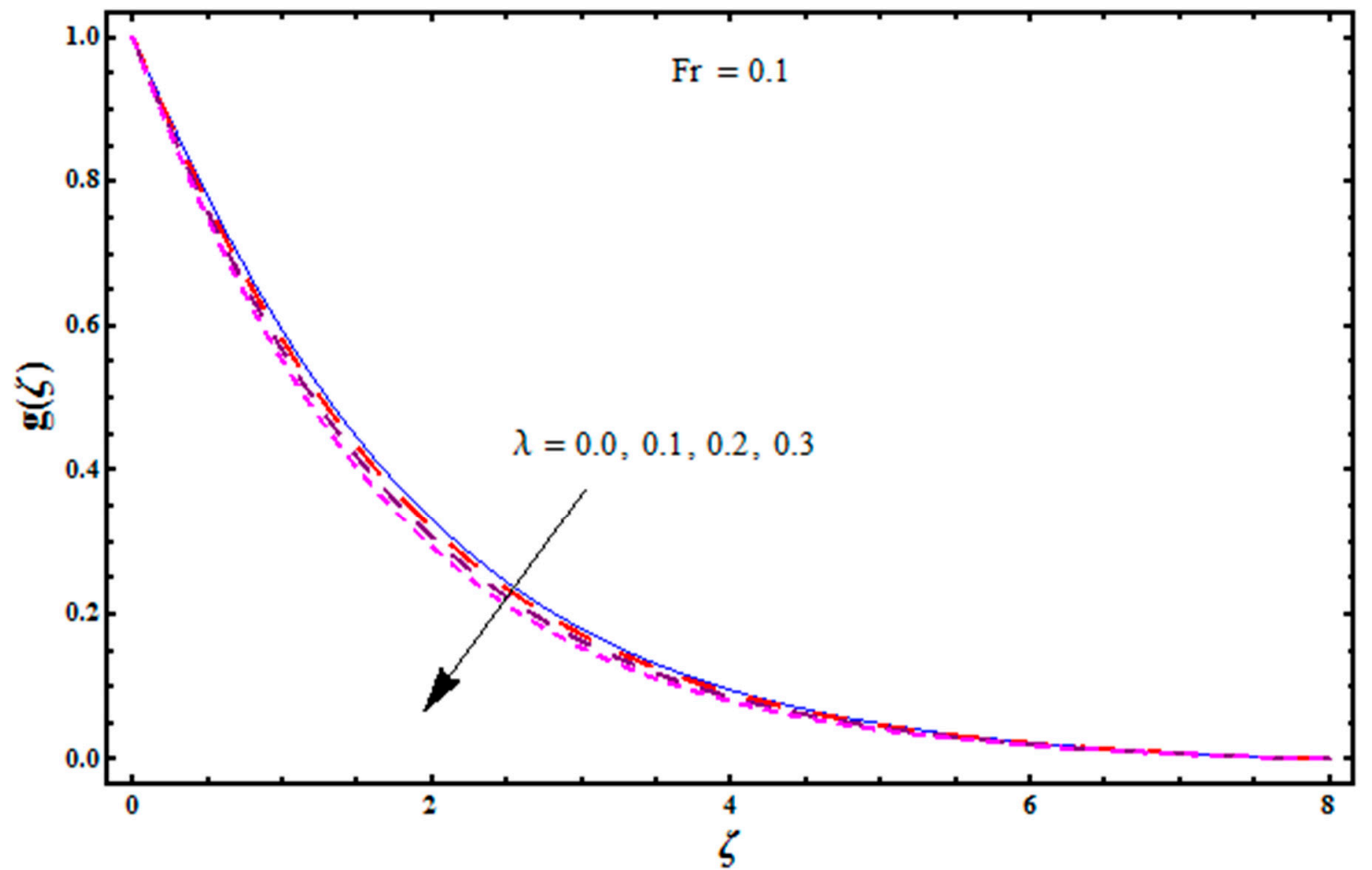

Figure 4. Curves of $g(\zeta)$ for $\lambda$. 


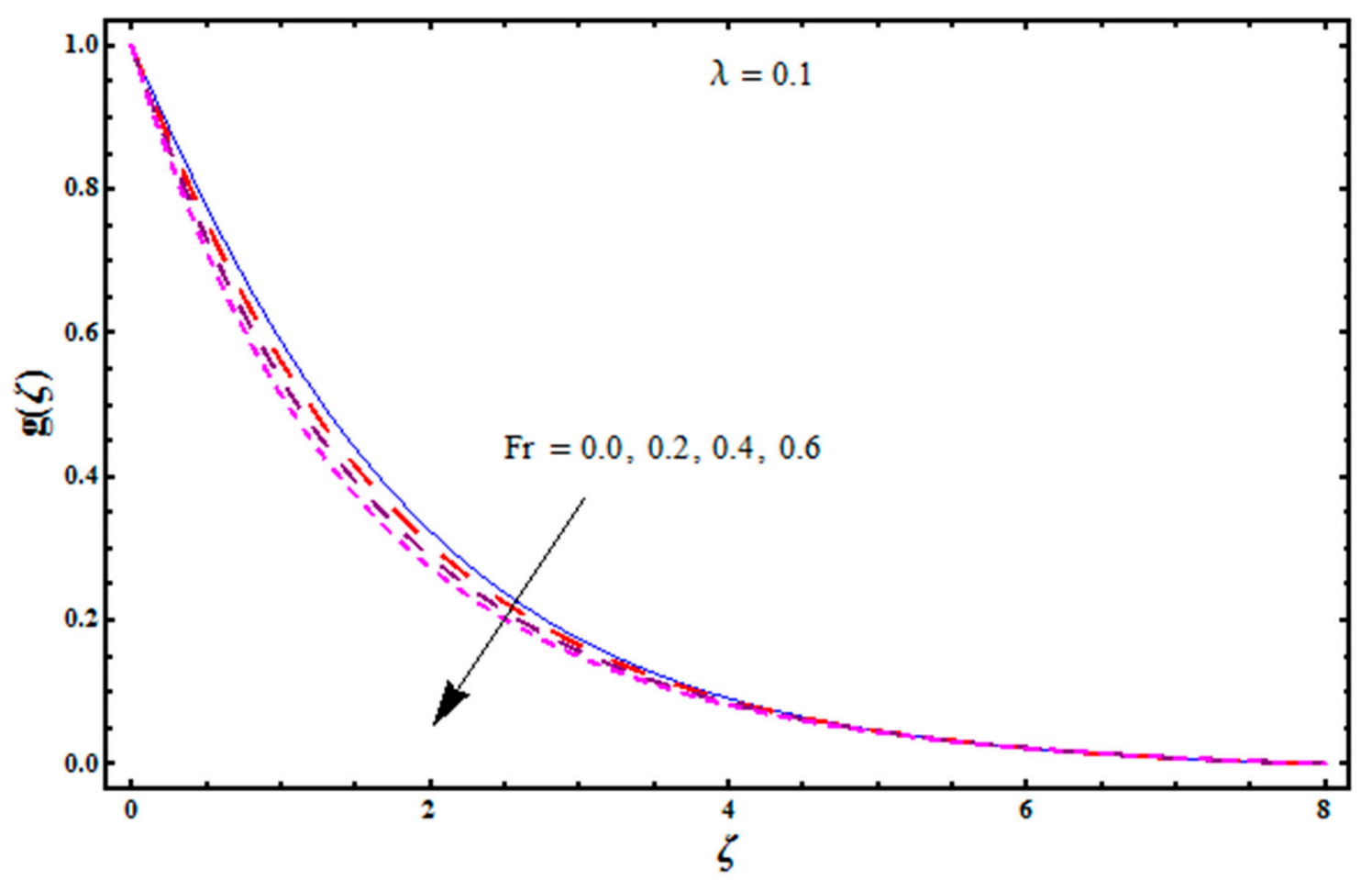

Figure 5. Curves of $g(\zeta)$ for $F r$.

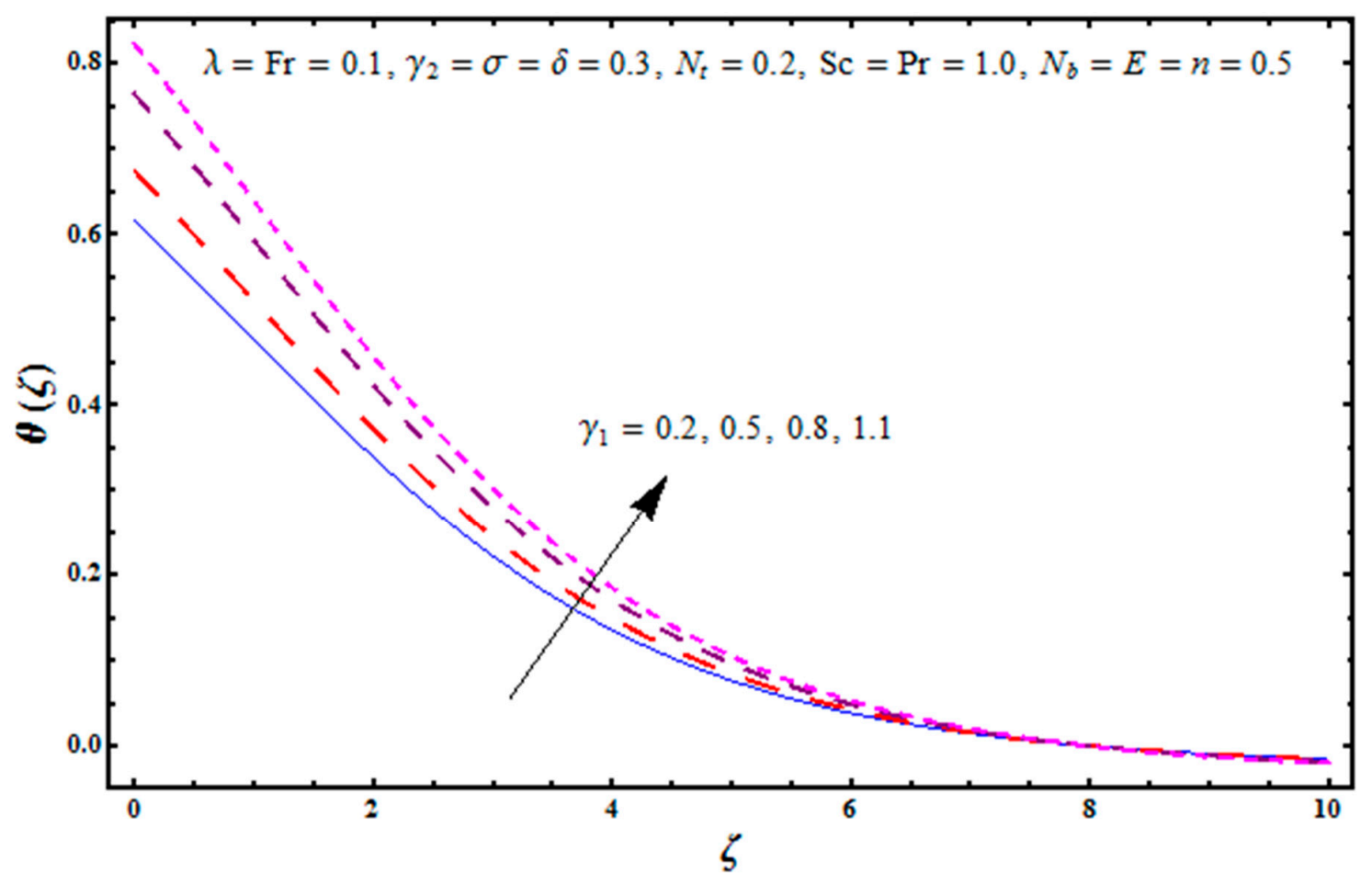

Figure 6. Curves of $\theta(\zeta)$ for $\gamma_{1}$. 


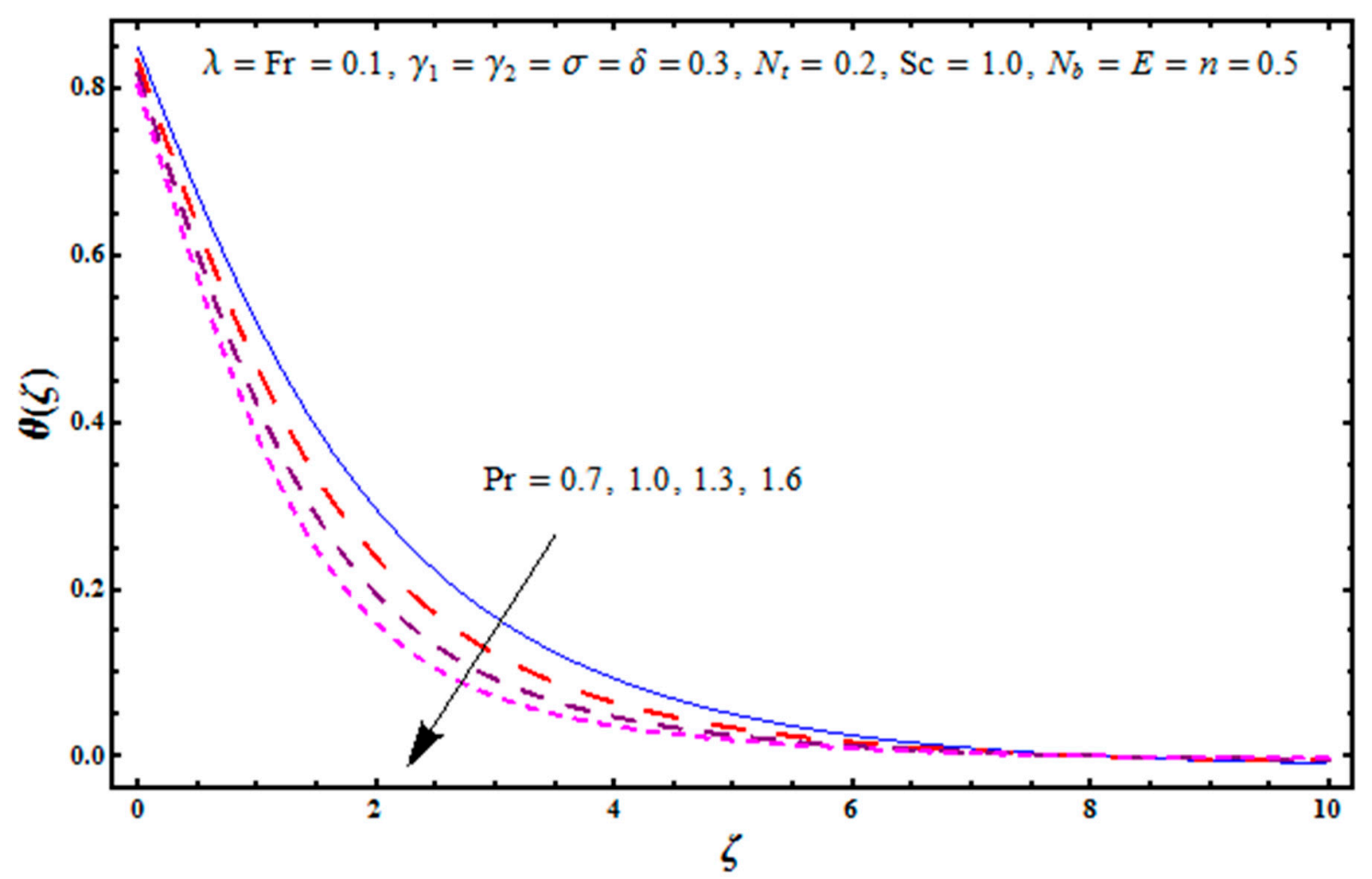

Figure 7. Curves of $\theta(\zeta)$ for Pr.

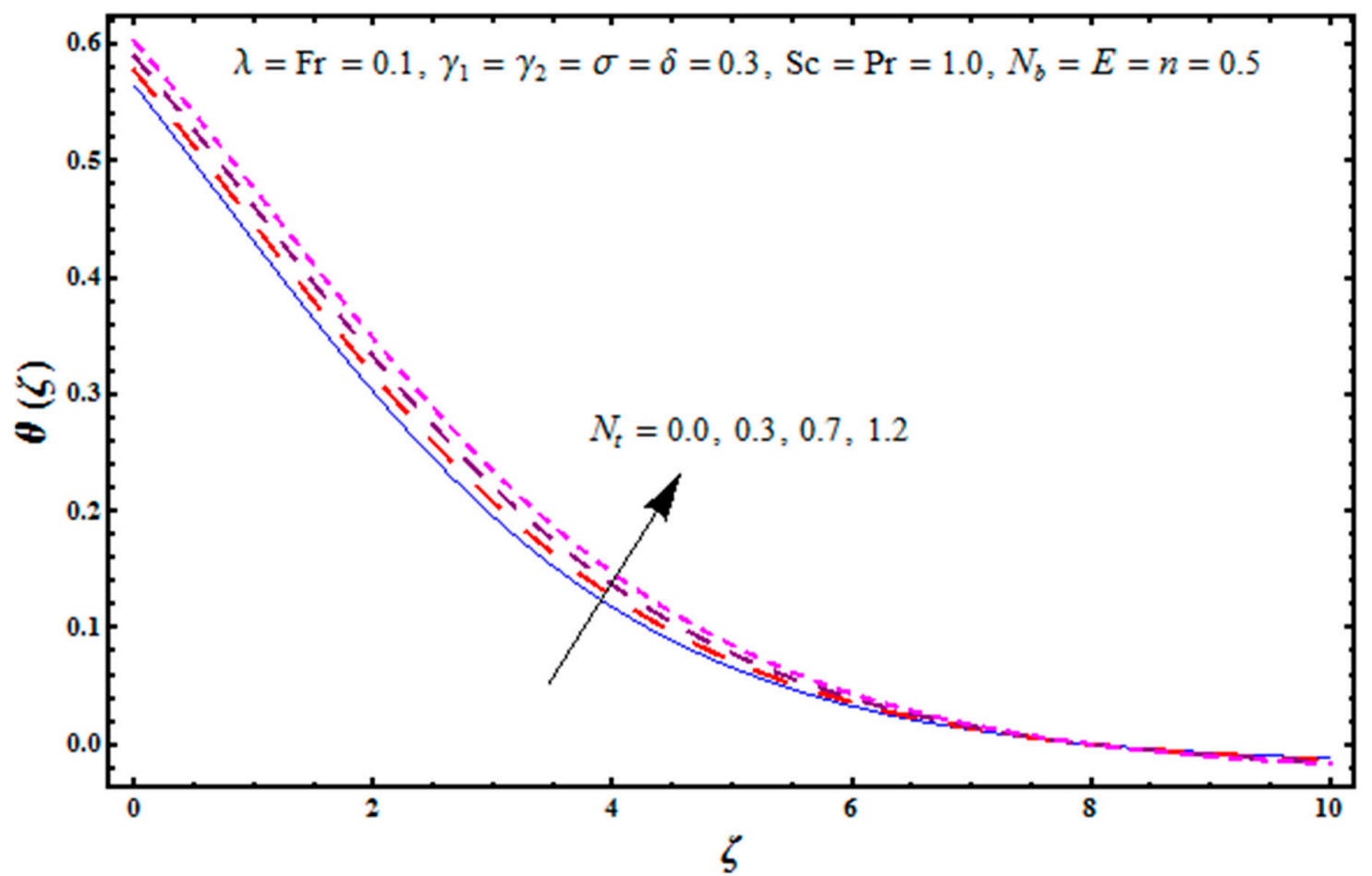

Figure 8. Curves of $\theta(\zeta)$ for $N_{t}$. 


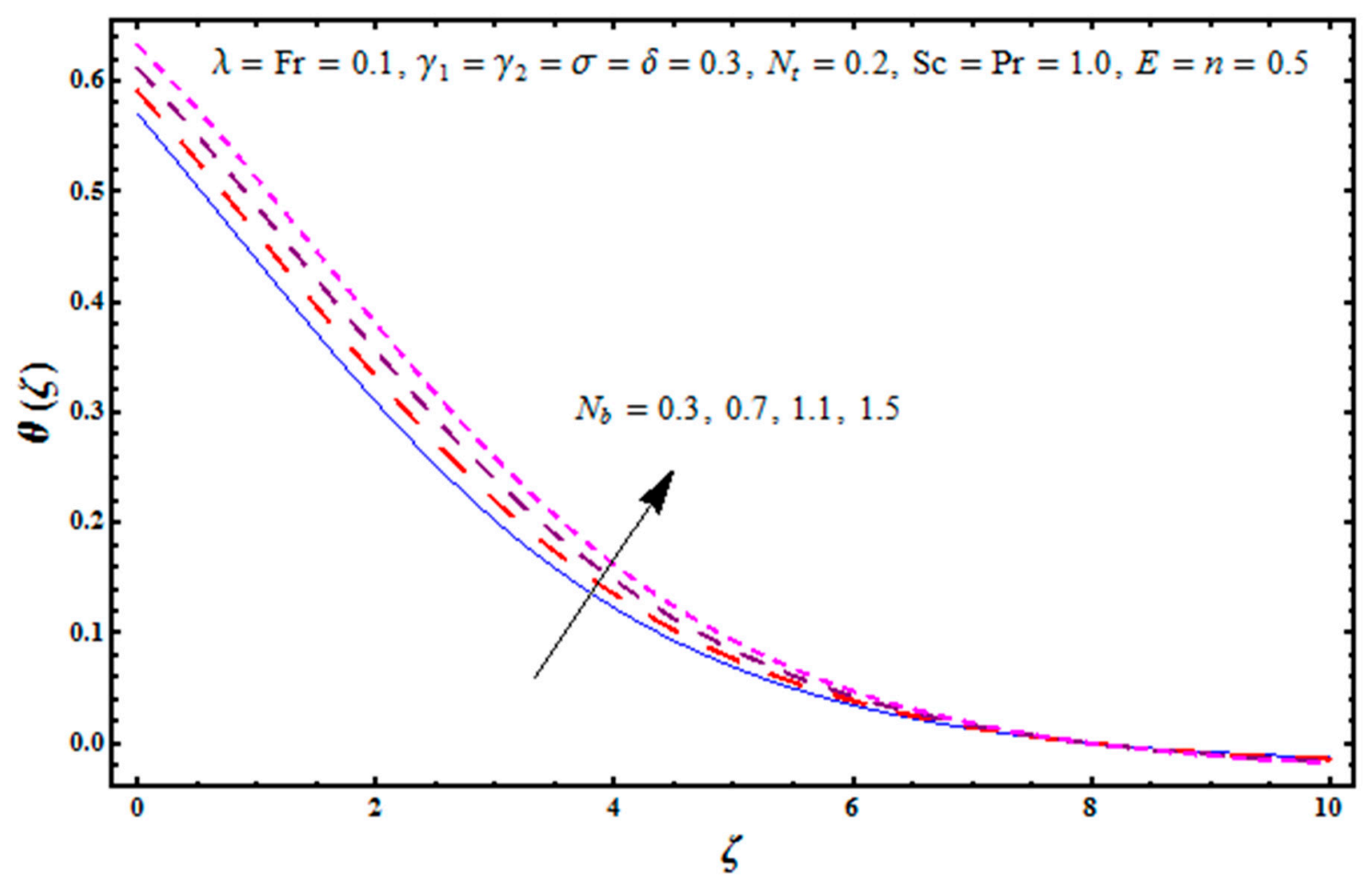

Figure 9. Curves of $\theta(\zeta)$ for $N_{b}$.

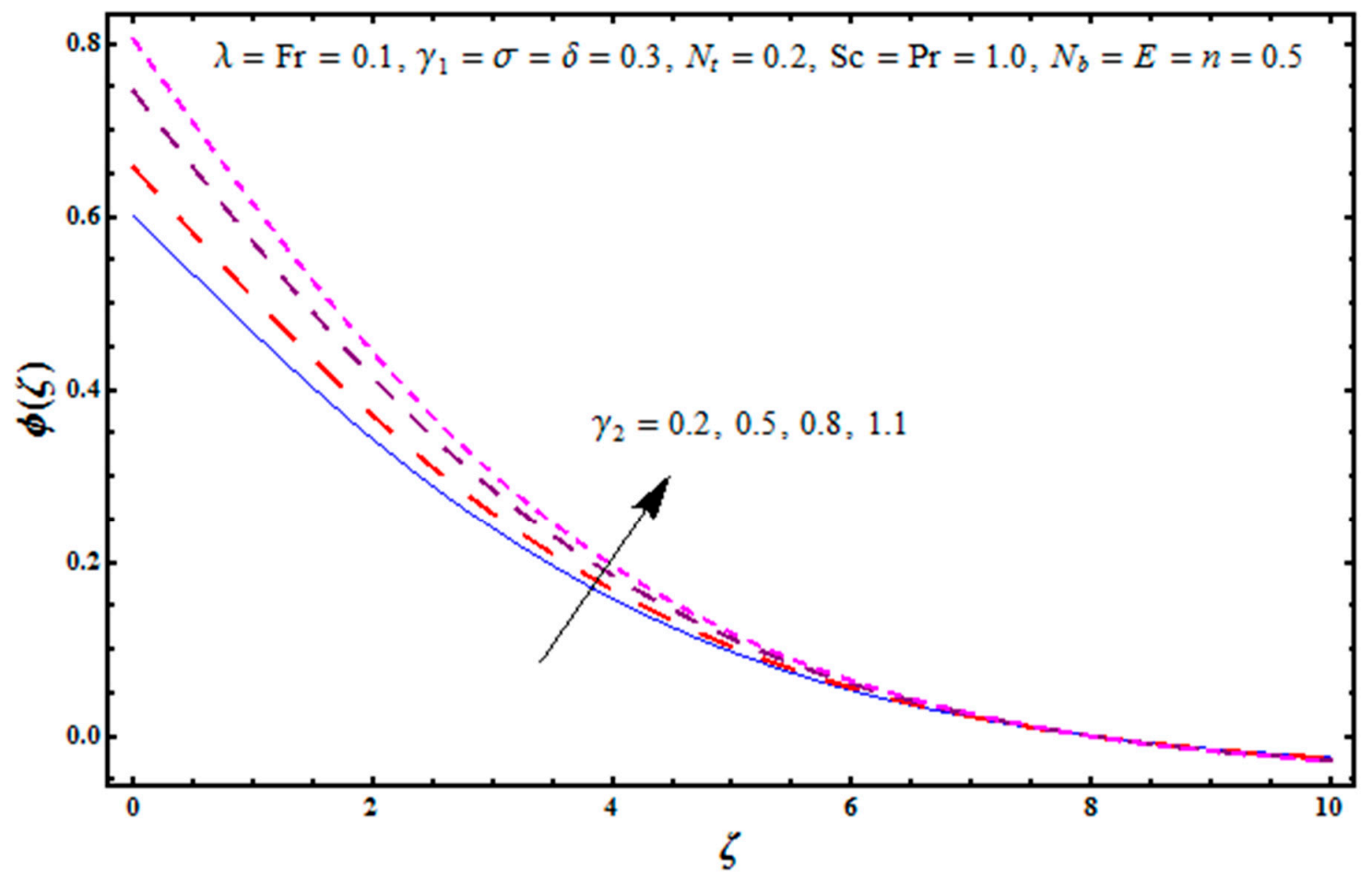

Figure 10. Curves of $\phi(\zeta)$ for $\gamma_{2}$. 


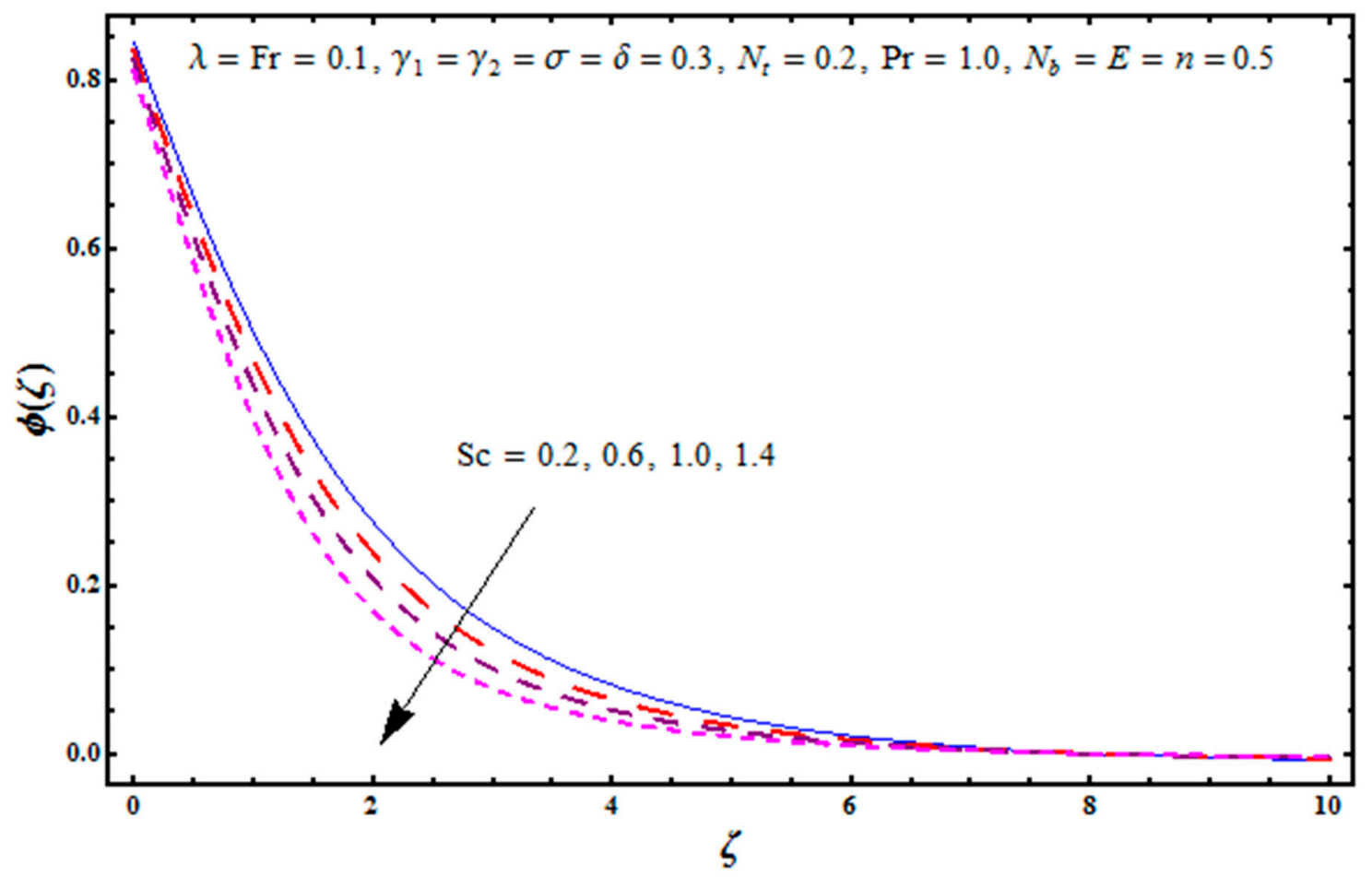

Figure 11. Curves of $\phi(\zeta)$ for $S c$.

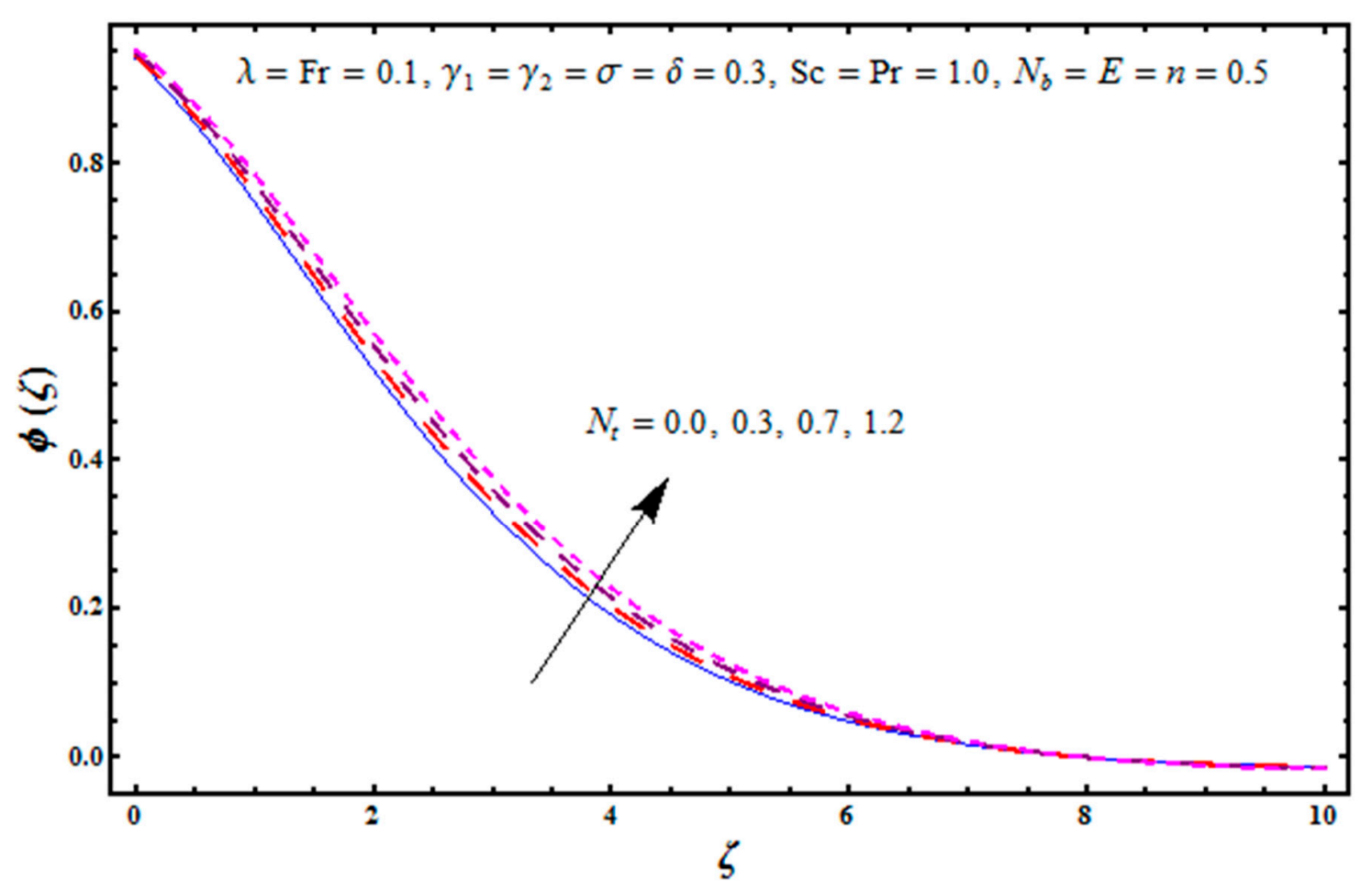

Figure 12. Curves of $\phi(\zeta)$ for $N_{t}$. 


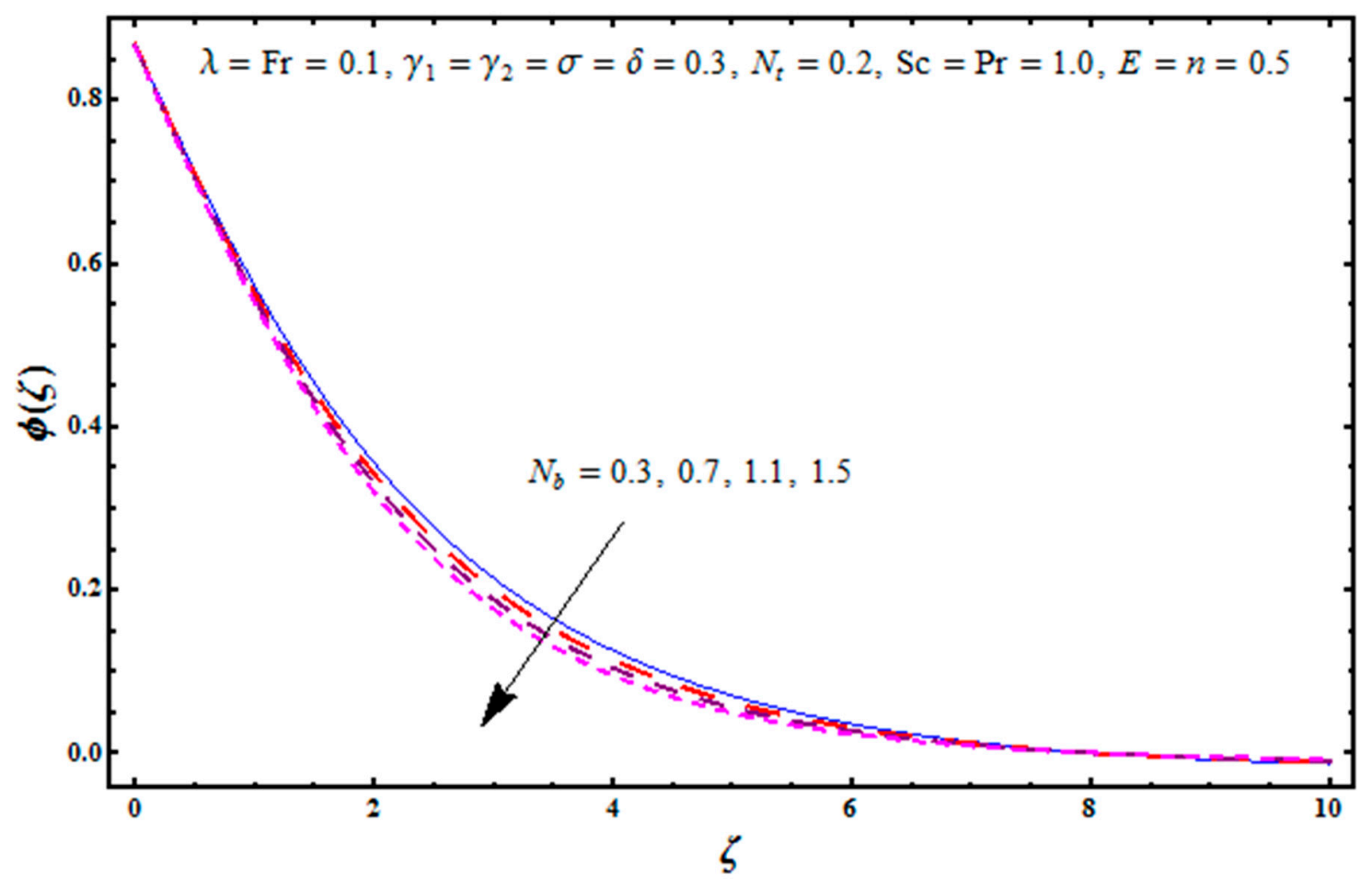

Figure 13. Curves of $\phi(\zeta)$ for $N_{b}$.

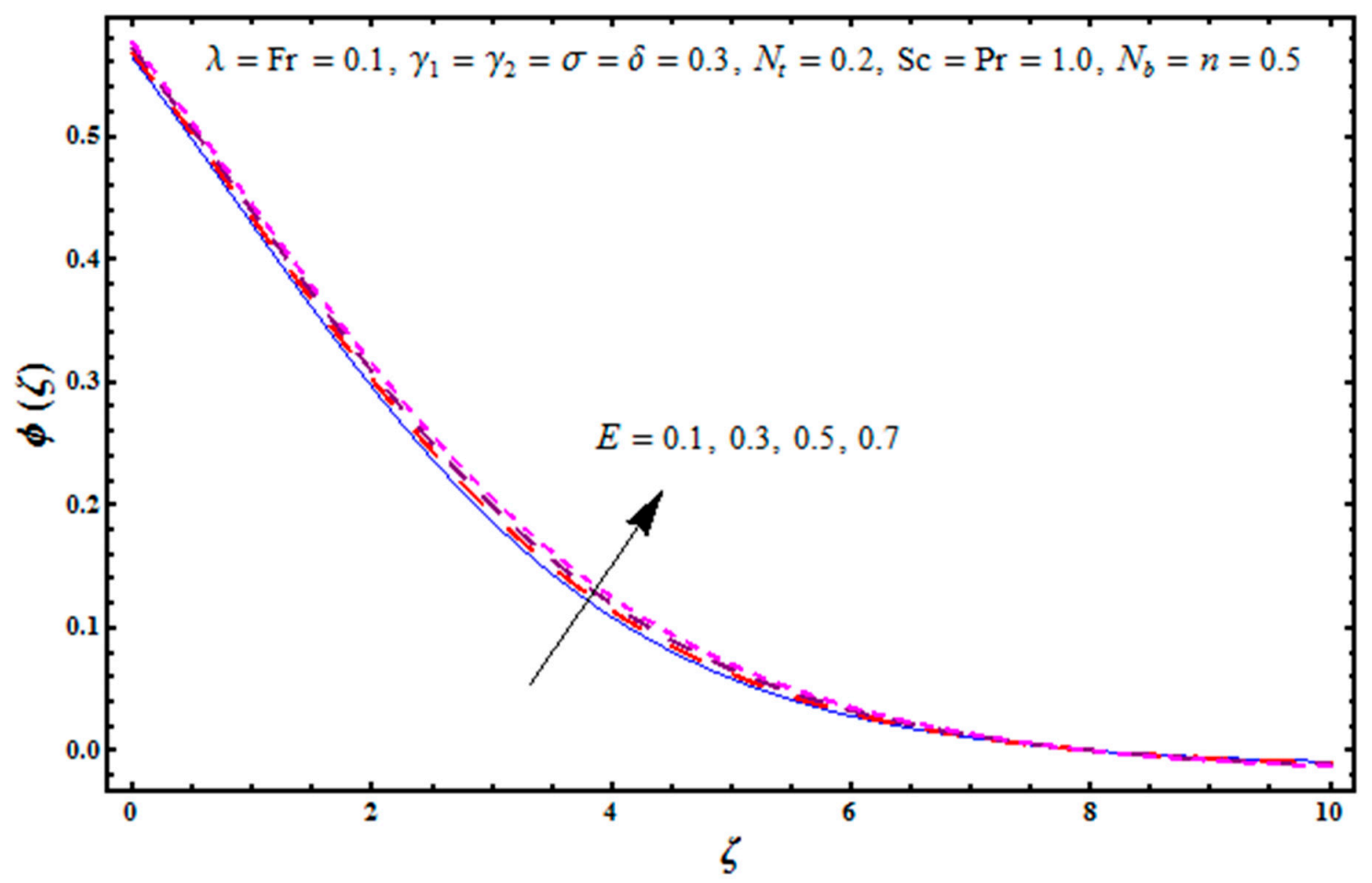

Figure 14. Curves of $\phi(\zeta)$ for $E$. 


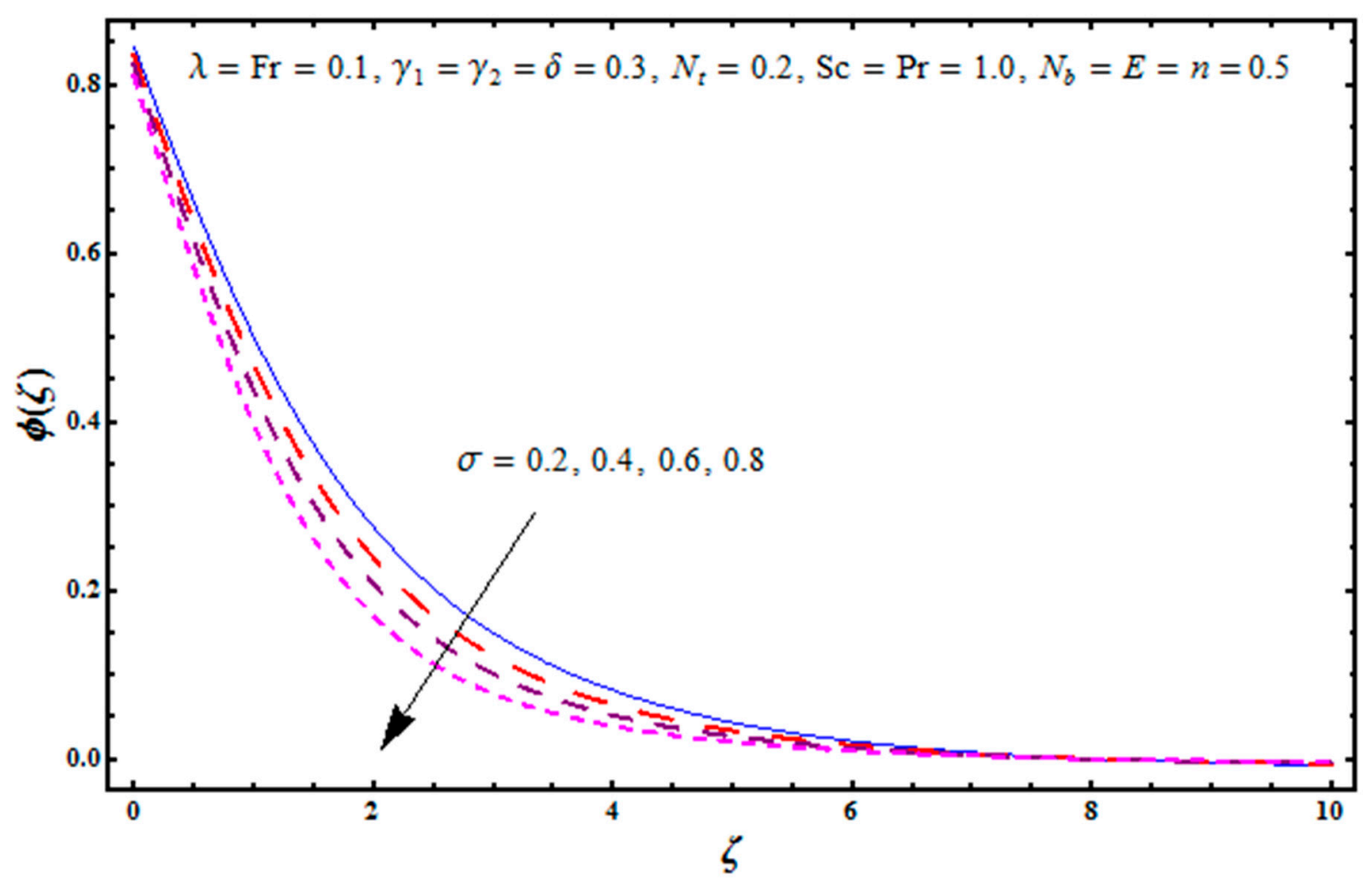

Figure 15. Curves of $\phi(\zeta)$ for $\sigma$.

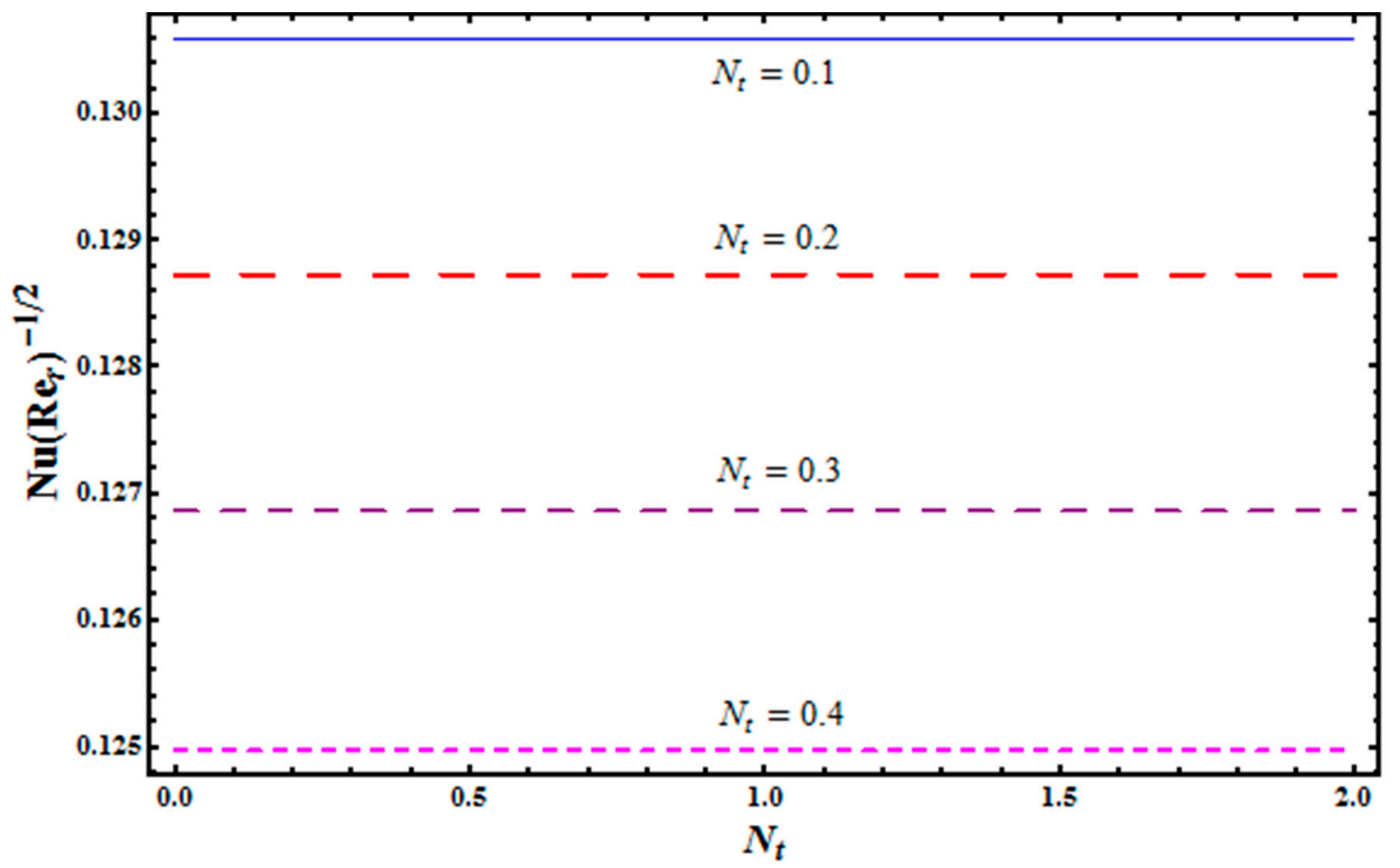

Figure 16. Curves of $N u\left(\operatorname{Re}_{r}\right)^{-1 / 2}$ for $N_{t}$. 


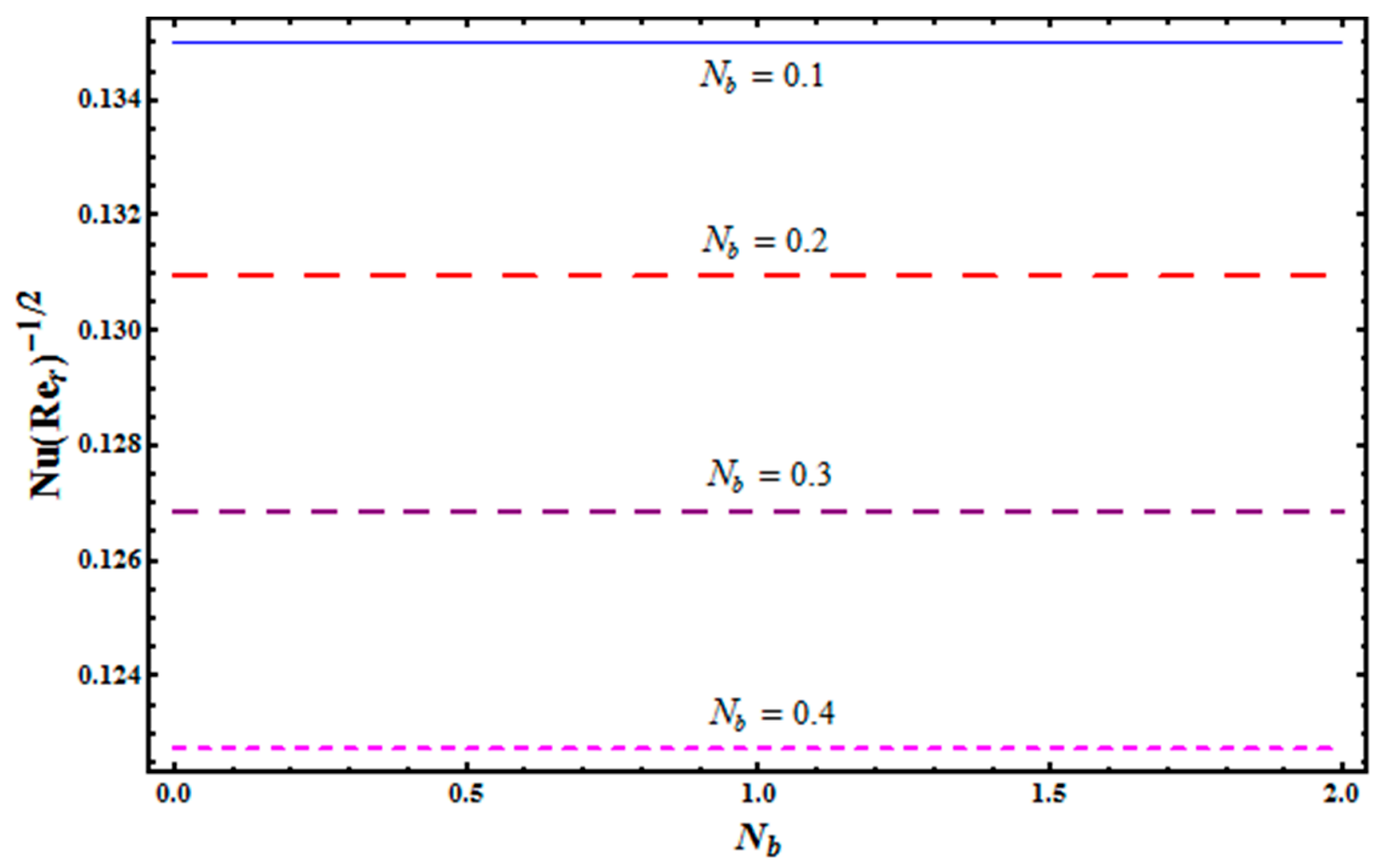

Figure 17. Curves of $N u\left(\operatorname{Re}_{r}\right)^{-1 / 2}$ for $N_{b}$.

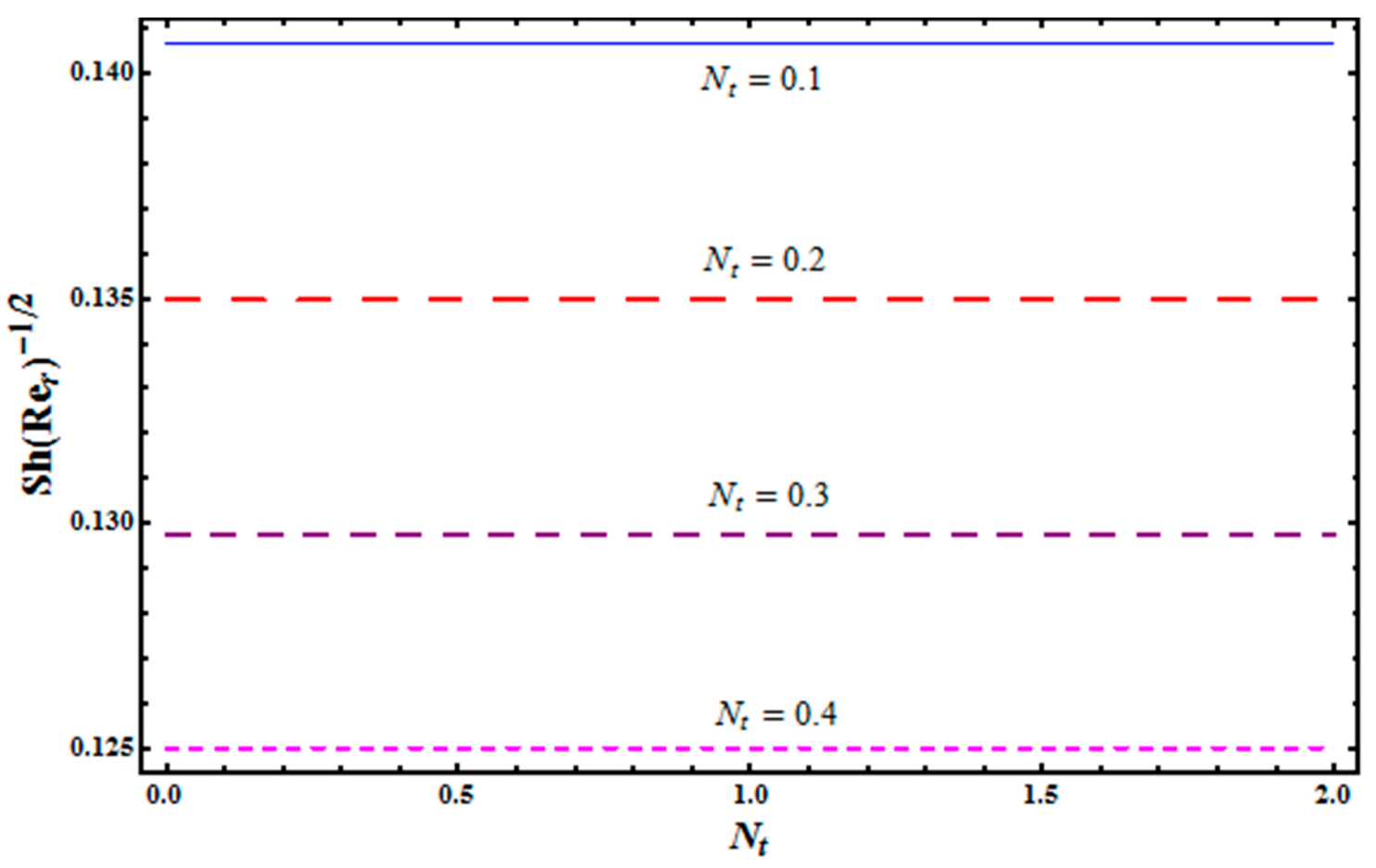

Figure 18. Curves of $\operatorname{Sh}\left(\operatorname{Re}_{r}\right)^{-1 / 2}$ for $N_{t}$. 


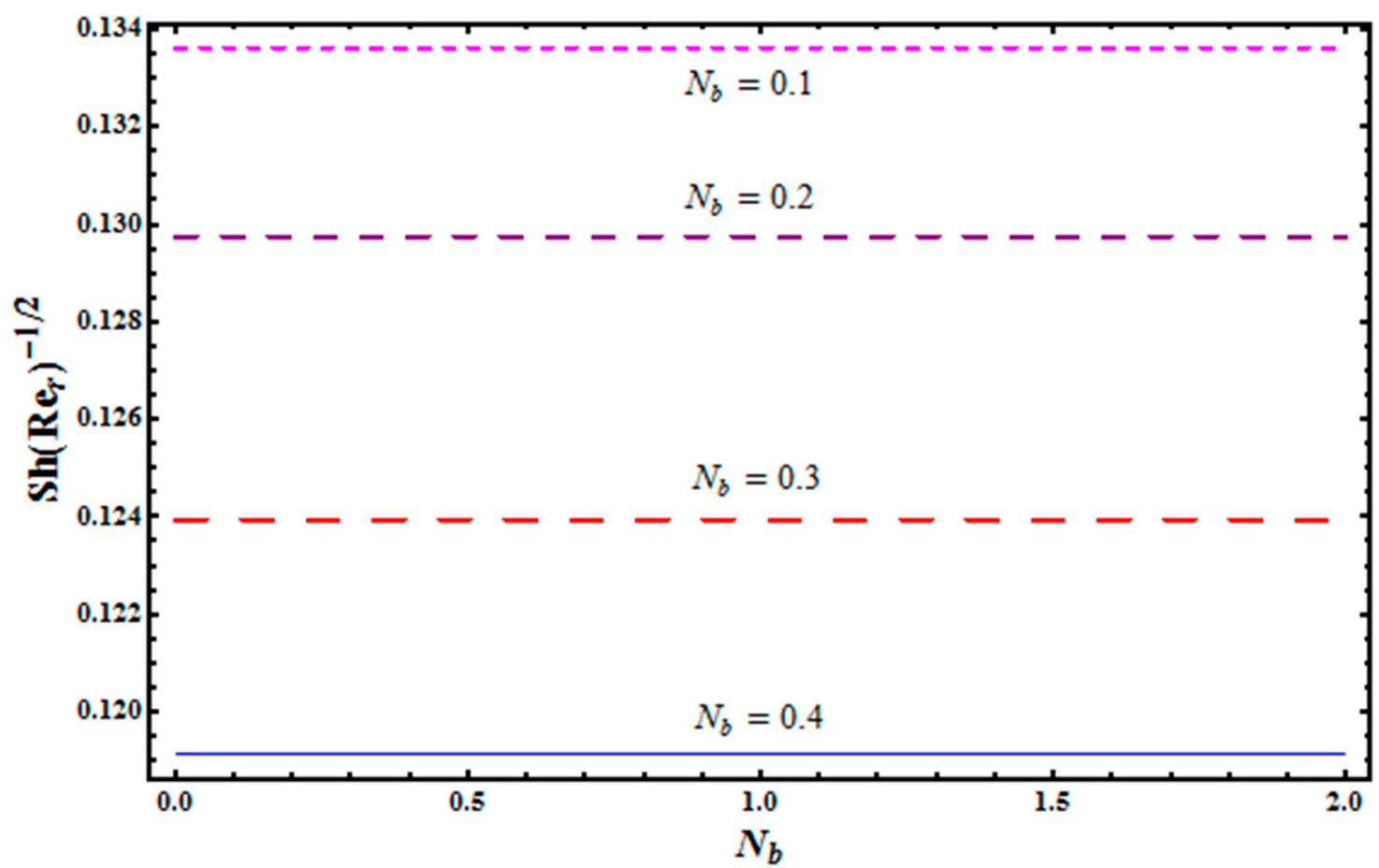

Figure 19. Curves of $\operatorname{Sh}\left(\operatorname{Re}_{r}\right)^{-1 / 2}$ for $N_{b}$.

Table 1. Comparative values of $f^{\prime \prime}(0)$ and $g^{\prime}(0)$ for value of $F r$ when $\lambda=0.2$.

\begin{tabular}{ccccc}
\hline & \multicolumn{2}{c}{ Present Results } & \multicolumn{2}{c}{ Naqvi et al. [48] } \\
\hline$F r$ & $f^{\prime \prime}(0)$ & $g^{\prime}(0)$ & $f^{\prime \prime}(0)$ & $g^{\prime}(0)$ \\
0.2 & 0.43478 & -0.78139 & 0.4347813 & -0.7813904 \\
\hline
\end{tabular}

\section{Conclusions}

Darcy-Forchheimer flow of viscous nanofluid due to a rotating disk with binary chemical reaction and Arrhenius activation energy was studied. The shooting algorithm leads to the solutions of dimensionless quantities. We noticed that temperature rises for larger thermal Biot number. Temperature is less in the absence of thermal Biot number. Enhancing concentration Biot number leads to higher concentration and thickness of concentration boundary layer. An increase in activation energy leads to higher temperature. We further demonstrated that enhancement in chemical reaction parameter gives a reduction in the curves of concentration.

Author Contributions: All the authors have contributed equally in all parts.

Funding: This research was funded by University of Malaya grant number IIRG 001C-2019.

Acknowledgments: The project is partially sponsored by University of Malaya grant No: IIRG 001C-2019.

Conflicts of Interest: The authors declare no conflict of interest.

\section{References}

1. Choi, S.U.S. Enhancing Thermal Conductivity of Fluids with Nanoparticles; FED 231/MD; ASME: New York, NY, USA, 1995; pp. 99-105.

2. Buongiorno, J. Convective transport in nanofluids. ASME J. Heat Transf. 2006, 128, 240-250. [CrossRef]

3. Tiwari, R.K.; Das, M.K. Heat transfer augmentation in a two-sided lid-driven differentially heated square cavity utilizing nanofluid. Int. J. Heat Mass Transf. 2007, 50, 2002-2018. [CrossRef]

4. Pantzali, M.N.; Mouza, A.A.; Paras, S.V. Investigating the efficacy of nanofluids as coolants in plate heat exchangers (PHE). Chem. Eng. Sci. 2009, 64, 3290-3300. [CrossRef] 
5. Sheikholeslami, M.; Bandpy, M.G.; Ganji, D.D.; Soleimani, S. Effect of a magnetic field on natural convection in an inclined half-anulus enclosure filled with Cu-water nanofluid using CVFEM. Adv. Powder Technol. 2013, 24, 980-991. [CrossRef]

6. Togun, H.; Safaei, M.R.; Sadri, R.; Kazi, S.N.; Badarudin, A.; Hooman, K.; Sadeghinezhad, E. Numerical simulation of laminar to turbulent nanofluid flow and heat transfer over a backward-facing step. Appl. Math. Comput. 2014, 239, 153-170. [CrossRef]

7. Hsiao, K.L. Nanofluid flow with multimedia physical features for conjugate mixed convection and radiation. Comp. Fluids 2014, 104, 1-8. [CrossRef]

8. Hayat, T.; Muhammad, T.; Alsaedi, A.; Alhuthali, M.S. Magnetohydrodynamic three-dimensional flow of viscoelastic nanofluid in the presence of nonlinear thermal radiation. J. Magn. Magn. Mater. 2015, 385, $222-229$. [CrossRef]

9. Lin, Y.; Zheng, L.; Zhang, X.; Ma, L.; Chen, G. MHD pseudo-plastic nanofluid unsteady flow and heat transfer in a finite thin film over stretching surface with internal heat generation. Int. J. Heat Mass Transf. 2015, 84, 903-911. [CrossRef]

10. Hsiao, K.L. Stagnation electrical MHD nanofluid mixed convection with slip boundary on a stretching sheet. Appl. Thermal Eng. 2016, 98, 850-861. [CrossRef]

11. Hayat, T.; Aziz, A.; Muhammad, T.; Alsaedi, A. On magnetohydrodynamic three-dimensional flow of nanofluid over a convectively heated nonlinear stretching surface. Int. J. Heat Mass Transf. 2016, 100, 566-572. [CrossRef]

12. Hayat, T.; Muhammad, T.; Shehzad, S.A.; Alsaedi, A. Three-dimensional flow of Jeffrey nanofluid with a new mass flux condition. J. Aerospace Eng. 2016, 29, 04015054. [CrossRef]

13. Hsiao, K.L. Micropolar nanofluid flow with MHD and viscous dissipation effects towards a stretching sheet with multimedia feature. Int. J. Heat Mass Transf. 2017, 112, 983-990. [CrossRef]

14. Muhammad, T.; Alsaedi, A.; Shehzad, S.A.; Hayat, T. A revised model for Darcy-Forchheimer flow of Maxwell nanofluid subject to convective boundary condition. Chin. J. Phys. 2017, 55, 963-976. [CrossRef]

15. Hayat, T.; Muhammad, T.; Shehzad, S.A.; Alsaedi, A. An analytical solution for magnetohydrodynamic Oldroyd-B nanofluid flow induced by a stretching sheet with heat generation/absorption. Int. J. Thermal Sci. 2017, 111, 274-288. [CrossRef]

16. Hsiao, K.L. To promote radiation electrical MHD activation energy thermal extrusion manufacturing system efficiency by using Carreau-Nanofluid with parameters control method. Energy 2017, 130, 486-499. [CrossRef]

17. Hayat, T.; Sajjad, R.; Alsaedi, A.; Muhammad, T.; Ellahi, R. On squeezed flow of couple stress nanofluid between two parallel plates. Results Phys. 2017, 7, 553-561. [CrossRef]

18. Muhammad, T.; Alsaedi, A.; Hayat, T.; Shehzad, S.A. A revised model for Darcy-Forchheimer three-dimensional flow of nanofluid subject to convective boundary condition. Results Phys. 2017, 7, 2791-2797. [CrossRef]

19. Moshizi, S.A.; Zamani, M.; Hosseini, S.J.; Malvandi, A. Mixed convection of magnetohydrodynamic nanofluids inside microtubes at constant wall temperature. J. Magn. Magn. Mater. 2017, 430, 36-46. [CrossRef]

20. Hayat, T.; Hussain, Z.; Alsaedi, A.; Muhammad, T. An optimal solution for magnetohydrodynamic nanofluid flow over a stretching surface with constant heat flux and zero nanoparticles flux. Neural Comp. Appl. 2018, 29, 1555-1562. [CrossRef]

21. Eid, M.R.; Mahny, K.L.; Muhammad, T.; Sheikholeslami, M. Numerical treatment for Carreau nanofluid flow over a porous nonlinear stretching surface. Results Phys. 2018, 8, 1185-1193. [CrossRef]

22. Aziz, A.; Alsaedi, A.; Muhammad, T.; Hayat, T. Numerical study for heat generation/absorption in flow of nanofluid by a rotating disk. Results Phys. 2018, 8, 785-792. [CrossRef]

23. Muhammad, T.; Lu, D.C.; Mahanthesh, B.; Eid, M.R.; Ramzan, M.; Dar, A. Significance of Darcy-Forchheimer porous medium in nanofluid through carbon nanotubes. Commun. Theoret. Phys. 2018, 70, 361. [CrossRef]

24. Saif, R.S.; Hayat, T.; Ellahi, R.; Muhammad, T.; Alsaedi, A. Darcy-Forchheimer flow of nanofluid due to a curved stretching surface. Int. J. Numer. Methods Heat Fluid Flow 2019, 29, 2-20. [CrossRef]

25. Mahanthesh, B.; Gireesha, B.J.; Animasaun, I.L.; Muhammad, T.; Shashikumar, N.S. MHD flow of SWCNT and MWCNT nanoliquids past a rotating stretchable disk with thermal and exponential space dependent heat source. Phys. Scr. 2019, 94, 085214. [CrossRef]

26. von Karman, T. Uberlaminare und turbulente Reibung. Z. Angew. Math. Mech. 1921, 1, 233-252. [CrossRef]

27. Cochran, W.G. The flow due to a rotating disk. Proc. Camb. Philos. Soc. 1934, 30, 365-375. [CrossRef] 
28. Stewartson, K. On the flow between two rotating coaxial disks. Proc. Comb. Phil. Soc. 1953, 49, 333-341. [CrossRef]

29. Chapple, P.J.; Stokes, V.K. On the Flow Between a Rotating and a Stationary Disk; Report No. FLD 8; Dept. Mech. Eng. Princeton University: Princeton, NJ, USA, 1962.

30. Ackroyd, J.A.D. On the steady flow produced by a rotating disk with either surface suction or injection. J. Eng. Math. 1978, 12, 207-220. [CrossRef]

31. Erdogan, M.E. Unsteady flow of a viscous fluid due to non-coaxial rotations of a disk and a fluid at infinity. Int. J. Non-Linear Mech. 1997, 32, 285-290. [CrossRef]

32. Attia, H.A. Steady flow over a rotating disk in porous medium with heat transfer. Nonlinear Anal. Model. Control $2009,14,21-26$.

33. Turkyilmazoglu, M.; Senel, P. Heat and mass transfer of the flow due to a rotating rough and porous disk. Int. J. Thermal Sci. 2013, 63, 146-158. [CrossRef]

34. Rashidi, M.M.; Kavyani, N.; Abelman, S. Investigation of entropy generation in MHD and slip flow over a rotating porous disk with variable properties. Int. J. Heat Mass Transf. 2014, 70, 892-917. [CrossRef]

35. Mustafa, M.; Khan, J.A.; Hayat, T.; Alsaedi, A. On Bodewadt flow and heat transfer of nanofluids over a stretching stationary disk. J. Mol. Liq. 2015, 211, 119-125. [CrossRef]

36. Hayat, T.; Muhammad, T.; Shehzad, S.A.; Alsaedi, A. On magnetohydrodynamic flow of nanofluid due to a rotating disk with slip effect: A numerical study. Comput. Methods Appl. Mech. Eng. 2017, 315, 467-477. [CrossRef]

37. Mustafa, M. MHD nanofluid flow over a rotating disk with partial slip effects: Buongiorno model. Int. J. Heat Mass Transf. 2017, 108, 1910-1916. [CrossRef]

38. Hayat, T.; Haider, F.; Muhammad, T.; Alsaedi, A. On Darcy-Forchheimer flow of carbon nanotubes due to a rotating disk. Int. J. Heat Mass Transf. 2017, 112, 248-254. [CrossRef]

39. Bestman, A.R. Natural convection boundary layer with suction and mass transfer in a porous medium. Int. J. Energy Res. 1990, 14, 389-396. [CrossRef]

40. Makinde, O.D.; Olanrewaju, P.O.; Charles, W.M. Unsteady convection with chemical reaction and radiative heat transfer past a flat porous plate moving through a binary mixture. Africka Matematika 2011, 22, 65-78. [CrossRef]

41. Maleque, K.A. Effects of exothermic/endothermic chemical reactions with Arrhenius activation energy on MHD free convection and mass transfer flow in presence of thermal radiation. J. Thermodyn. 2013, 2013, 692516. [CrossRef]

42. Awad, F.G.; Motsa, S.; Khumalo, M. Heat and mass transfer in unsteady rotating fluid flow with binary chemical reaction and activation energy. PLoS ONE 2014, 9, e107622. [CrossRef] [PubMed]

43. Abbas, Z.; Sheikh, M.; Motsa, S.S. Numerical solution of binary chemical reaction on stagnation point flow of Casson fluid over a stretching/shrinking sheet with thermal radiation. Energy 2016, 95, 12-20. [CrossRef]

44. Shafique, Z.; Mustafa, M.; Mushtaq, A. Boundary layer flow of Maxwell fluid in rotating frame with binary chemical reaction and activation energy. Results Phys. 2016, 6, 627-633. [CrossRef]

45. Hayat, T.; Aziz, A.; Muhammad, T.; Alsaedi, A. Effects of binary chemical reaction and Arrhenius activation energy in Darcy-Forchheimer three-dimensional flow of nanofluid subject to rotating frame. J. Thermal Anal. Calorimet. 2019, 136, 1769-1779. [CrossRef]

46. Irfan, M.; Khan, W.A.; Khan, M.; Gulzar, M.M. Influence of Arrhenius activation energy in chemically reactive radiative flow of 3D Carreau nanofluid with nonlinear mixed convection. J. Phys. Chem. Solids 2019, 125, 141-152. [CrossRef]

47. Hayat, T.; Aziz, A.; Muhammad, T.; Alsaedi, A. Numerical simulation for Darcy-Forchheimer 3D rotating flow subject to binary chemical reaction and Arrhenius activation energy. J. Cent. South Univ. 2019, 26, 1250-1259. [CrossRef]

48. Naqvi, S.M.R.S.; Muhammad, T.; Kim, H.M.; Mahmood, T.; Saeed, A.; Khan, B.S. Numerical treatment for Darcy-Forchheimer flow of nanofluid due to a rotating disk with slip effects. Can. J. Phys. 2019, 97, 856-863. [CrossRef]

(c) 2019 by the authors. Licensee MDPI, Basel, Switzerland. This article is an open access article distributed under the terms and conditions of the Creative Commons Attribution (CC BY) license (http:/ / creativecommons.org/licenses/by/4.0/). 